\title{
Medical audit of rectal biopsy diagnosis of inflammatory bowel disease
}

\author{
JV FREI, * BC MORSON \\ From the Department of Pathology, St Mark's Hospital, London EC1V 2PS
}

SUMMARY The records of the rectal biopsy diagnoses of ulcerative colitis and Crohn's disease in the Department of Pathology, St Mark's Hospital, London, were reviewed. The biopsy diagnoses were compared to subsequent resection diagnoses on the same patients, and annual and seasonal variations in the frequency of these and related diagnoses were studied. The accuracy rate for the biopsy diagnosis of ulcerative colitis was about $70 \%$ and for Crohn's disease about $40 \%$ each time a biopsy was read. The low figure for the accuracy rate for Crohn's disease could be attributed to sampling error inherent in the diagnosis of a disease which is essentially patchy, showing discontinuous pathology. Also, many patients with Crohn's disease have a normal rectum which is biopsied to demonstrate the distinction from ulcerative colitis. In practical terms therefore a $40 \%$ accuracy rate in Crohn's disease is probably adequate. The rate of "false-positive" diagnoses was about $5 \%$. There was a seasonal variation in the frequency of these two diagnoses, but no variation attributable to changes in observers, as pathology trainees in the Department change regularly. The frequency of diagnoses of non-specific inflammation and of normal colon did show such non-random variations.

The colorectum is the site of two common, clinically and pathologically separable inflammatory diseases of unknown aetiology: ulcerative colitis and Crohn's disease. ${ }^{1}$ In a biopsy or in a resection specimen, however, the pathologist may not always be able to determine which of the two diseases is present. Occasionally this uncertainty exists even when clinical information is available and when other entities have been excluded from the differential diagnosis.

These two inflammatory colitides have been intensively studied at St Mark's Hospital for many years. ${ }^{2}$ The volume and experience of hospital and consultation specimens is considerable, but as the Department is a major training centre for the diagnosis of colorectal diseases, the diagnosis was, in many cases, made by trainee pathologists. Thus the possibility exists of variations in the accuracy of diagnosis. The recent records of the Pathology Department were examined to determine the levels of accuracy and of consistency of the biopsy diagnosis of ulcerative colitis and Crohn's disease.

\footnotetext{
*Permanent address: Department of Pathology, University Hospital, London, Ontario, Canada N6A 5C1.
}

Accepted for publication 8 July 1981

\section{Material and methods}

The records were examined in two different ways. The first was to analyse the Pathology Department records of patients who had had surgical removal of bowel (small or large intestine or both) for nonspecific inflammatory bowel disease between January 1978 and October 1980. There were 126 cases diagnosed as ulcerative colitis, Crohn's disease or indeterminate colitis. Of these, the records of 79 cases showed one or more previous diagnostic biopsies in addition to the resection. The reasons for performing multiple biopsies included the need in some patients for follow-up examination, attempts at clarification of an equivocal diagnosis, judging response to treatment, detecting epithelial dysplasia, and determining recurrence of disease.

Brief clinical information was sometimes available on the request form when the biopsies were first reported. This took the form of ? colitis, ? Crohn's disease or ? inflammatory bowel disease. Occasionally a brief description was given of symptomatology (such as diarrhoea and bleeding) and endoscopic changes, accompanied by a clinical opinion such as "looks like Crohn's disease." It was exceptional for a request form to give an unequivocal diagnosis of 
one disease, even if it had already been established by investigation at another hospital or at St Mark's. Mostly the request forms contained minimal or no clinical information which might have biased the reporting pathologist. Nevertheless a histological opinion on a rectal biopsy cannot be completely shielded from the risk of diagnostic bias because of information given on a request form. But this bias can work both ways, either to the wrong or to the correct diagnosis. Because of the large volume of rectal biopsy work in this department it is very exceptional for a biopsy to be reported towards a particular diagnosis under direct pressure from clinical opinion. It is very doubtful whether biopsy reports were at all significantly influenced by clinical information available at the time, but objective measurement of this is impossible to assess retrospectively, if only because of the inadequate and unreliable amount of clinical information usually given.

Biopsy diagnoses were retrieved from the records without re-examination of the histological slides or of hospital records. The original reports expressed variable diagnostic conviction and differed in wording. One of us (JVF) read all the reports and found that the intended message was clear nevertheless and that this allowed the assignment of the reports into five diagnostic categories: ulcerative colitis, Crohn's disease, indeterminate colitis, normal or bacterial colitis. Reports on biopsies which were regarded as inadequate for interpretation and those made on parts of the bowel other than the rectum were excluded. The resection and biopsy diagnoses were then compared.

The second procedure was to count the number of times these same biopsy diagnoses (except bacterial colitis) were made in two-monthly periods from January 1978 to December 1979 in order to assess the effect of changing trainees. Two other diagnostic categories were also counted: adenocarcinoma of rectum and rectal adenoma (excluding cases of familial polyposis). These two categories were added in the hope that because of more clear-cut criteria for diagnosis, they would act as internal controls of consistency of the records. The counts of the various categories were compared by the $\chi^{2}$ test. $^{3}$

\section{Results}

The comparison of diagnoses on resection cases and biopsy specimens are shown in the first two tables. Table 1 compares the first biopsy diagnosis with the resection diagnosis. In ulcerative colitis there is agreement between the two for about two thirds of the cases; in Crohn's disease in about two fifths. The level of agreement is a measure of the accuracy of diagnosis. Accuracy remains the same when multiple biopsies including the first one are compared with the resection diagnosis (Table 2 ). In only about $5 \%$ of cases, both of the two main diagnoses have been made on biopsy tissue from the same patient at different times. This represents the level of "falsepositive" diagnosis. Most of the other disagreements were between the biopsy diagnosis of indeterminate colitis or normal tissue and the resection diagnosis. Correspondingly, resected specimens diagnosed as indeterminate colitis had a biopsy diagnosis of ulcerative and Crohn's disease shared equally.

The bimonthly number of the various categories of biopsy diagnosis for two consecutive years is shown in Table 3. There were a total of 3679 diagnoses or

Table 1 Diagnostic accuracy of first biopsy diagnosis in non-specific inflammatory bowel disease, St Mark's Hospital 1978-1980

\begin{tabular}{|c|c|c|c|c|c|c|}
\hline \multirow[t]{2}{*}{ Diagnosis in resected specimen } & \multirow[t]{2}{*}{ No of cases } & \multicolumn{5}{|c|}{ First biopsy diagnosis } \\
\hline & & Normal & Bacterial & Indeterminate & Crohn's & Ulcerative \\
\hline $\begin{array}{l}\text { Crohn's } \\
\text { Ulcerative } \\
\text { Indeterminate }\end{array}$ & $\begin{array}{r}38 \\
36 \\
5\end{array}$ & $\begin{array}{r}10 \\
3 \\
0\end{array}$ & $\begin{array}{l}0 \\
1 \\
1\end{array}$ & $\begin{array}{r}14 \\
5 \\
0\end{array}$ & $\begin{array}{l}14(41 \%) \\
3 \\
1\end{array}$ & $\begin{array}{l}0 \\
24 \\
3\end{array}(67 \%)$ \\
\hline
\end{tabular}

Table 2 Diagnostic accuracy of multiple biopsies in non-specific inflammatory bowel disease, St Mark's Hospital 1978-1980

\begin{tabular}{|c|c|c|c|c|c|c|c|c|c|c|c|c|}
\hline \multirow{3}{*}{$\begin{array}{l}\text { Diagnosis in resected specimen } \\
\\
\text { Crohn's } \\
\text { Ulcerative } \\
\text { Indeterminate }\end{array}$} & \multirow{3}{*}{$\begin{array}{l}\text { No of cases } \\
\\
38 \\
36 \\
5\end{array}$} & \multicolumn{11}{|c|}{ No of biopsies and percent of diagnoses } \\
\hline & & \multicolumn{2}{|c|}{$\begin{array}{l}\text { Normal } \\
\text { No } \%\end{array}$} & \multicolumn{2}{|c|}{$\begin{array}{l}\text { Bacterial } \\
\text { No } \%\end{array}$} & \multicolumn{2}{|c|}{$\begin{array}{l}\text { Indeterminate } \\
\text { No } \%\end{array}$} & \multicolumn{2}{|c|}{$\begin{array}{l}\text { Ulcerative } \\
\text { No } \%\end{array}$} & \multicolumn{2}{|c|}{$\begin{array}{l}\text { Crohn's } \\
\text { No } \%\end{array}$} & $\begin{array}{c}\begin{array}{l}\text { Total No } \\
\text { of biopsies }\end{array} \\
89\end{array}$ \\
\hline & & $\begin{array}{r}26 \\
9 \\
1\end{array}$ & $\begin{array}{l}29 \\
7 \cdot 5 \\
7 \cdot 5\end{array}$ & $\begin{array}{l}0 \\
1 \\
1\end{array}$ & $\begin{array}{l}0 \\
1 \\
7 \cdot 5\end{array}$ & $\begin{array}{r}23 \\
16 \\
1\end{array}$ & $\begin{array}{l}26 \\
13 \\
7 \cdot 5\end{array}$ & $\begin{array}{r}4 \\
86 \\
5\end{array}$ & $\begin{array}{l}4 \cdot 5 \\
72 \\
38\end{array}$ & $\begin{array}{r}36 \\
8 \\
5\end{array}$ & $\begin{array}{l}40 \\
6 \cdot 5 \\
38\end{array}$ & $\begin{array}{r}89 \\
120 \\
13\end{array}$ \\
\hline
\end{tabular}


Table 3 Number of biopsy diagnoses of inflammatory and neoplastic colorectal disease

\begin{tabular}{|c|c|c|c|c|c|c|c|c|}
\hline Year & Months & $\begin{array}{l}\text { Ulcerative } \\
\text { colitis }\end{array}$ & $\begin{array}{l}\text { Crohn's } \\
\text { disease }\end{array}$ & $\begin{array}{l}\text { Indeterminate } \\
\text { colitis }\end{array}$ & Normal & Adenocarcinoma & Adenoma & Total \\
\hline 1978 & $\begin{array}{l}\text { Jan-Feb } \\
\text { Mar-Apr } \\
\text { May-Jun } \\
\text { Jul-Aug } \\
\text { Sep-Oct } \\
\text { Nov-Dec }\end{array}$ & $\begin{array}{l}104 \\
114 \\
137 \\
103 \\
137 \\
114\end{array}$ & $\begin{array}{l}40 \\
52 \\
37 \\
21 \\
26 \\
30\end{array}$ & $\begin{array}{l}33 \\
35 \\
42 \\
12 \\
31 \\
24\end{array}$ & $\begin{array}{l}42 \\
34 \\
62 \\
61 \\
61 \\
36\end{array}$ & $\begin{array}{l}19 \\
35 \\
26 \\
19 \\
24 \\
22\end{array}$ & $\begin{array}{l}42 \\
53 \\
49 \\
56 \\
61 \\
51\end{array}$ & $\begin{array}{l}280 \\
323 \\
353 \\
272 \\
340 \\
277\end{array}$ \\
\hline 1979 & $\begin{array}{l}\text { Jan-Feb } \\
\text { Mar-Apr } \\
\text { May-Jun } \\
\text { Jul-Aug } \\
\text { Sep-Oct } \\
\text { Nov-Dec }\end{array}$ & $\begin{array}{r}85 \\
121 \\
104 \\
111 \\
102 \\
89\end{array}$ & $\begin{array}{l}50 \\
47 \\
32 \\
22 \\
24 \\
30\end{array}$ & $\begin{array}{l}51 \\
38 \\
75 \\
57 \\
40 \\
57\end{array}$ & $\begin{array}{l}52 \\
68 \\
38 \\
56 \\
59 \\
53\end{array}$ & $\begin{array}{l}25 \\
33 \\
26 \\
23 \\
23 \\
17\end{array}$ & $\begin{array}{l}39 \\
50 \\
54 \\
66 \\
62 \\
55\end{array}$ & $\begin{array}{l}302 \\
357 \\
329 \\
335 \\
210 \\
301\end{array}$ \\
\hline
\end{tabular}

about 300 in each period of two months. Approximately one third were diagnosed as ulcerative colitis and one tenth as Crohn's disease. This is in contrast to an approximately equal number of cases in each category amongst the surgically resected specimens. Surgery was thus three times as common in Crohn's disease as in ulcerative colitis.

The $\chi^{2}$ test was used to judge whether the numbers of the various diagnoses were distributed in a random way in each two-month period. This was done by comparing the number of times each diagnosis was made to the number of all other diagnoses (Table 4) in each two-month period. The diagnoses of neoplastic disease were found to be randomly distributed as expected, but all the other diagnoses were not.

Table 4 Probability that biopsy diagnoses of inflammatory and neoplastic colorectal disease vary randomly with time

\begin{tabular}{lll}
\hline Comparison of & $x^{2 *}$ & Probability \\
\hline Ulcerative colitis to other diagnoses & $25 \cdot 73$ & $<0.01$ \\
Crohn's disease to other diagnoses & $41 \cdot 20$ & $<0.0001$ \\
Indeterminate colitis to other diagnoses & $76 \cdot 29$ & $<10^{-10}$ \\
Normal to other diagnoses & $28 \cdot 45$ & $<0.01$ \\
Adenocarcinoma to other diagnoses & $8 \cdot 74$ & NS \\
Adenoma to other diagnoses & 16.43 & NS \\
Adenocarcinoma to adenoma & 13.50 & NS \\
\hline
\end{tabular}

$* \mathrm{df}=11$.

Non-random factors therefore influence the rate at which the various diagnoses were made. Such nonrandom variations could be seasonal. The Figure shows that there was a consistent variation in the number of diagnoses of Crohn's disease throughout the year. This suggests, as an incidental observation, that exacerbations might be commonest in January to April and remission in July to October. By comparison, the numbers of diagnoses of ulcerative colitis showed a less distinct tendency to be made more often in the summer than in the winter. In this report the importance of these seasonal variations is

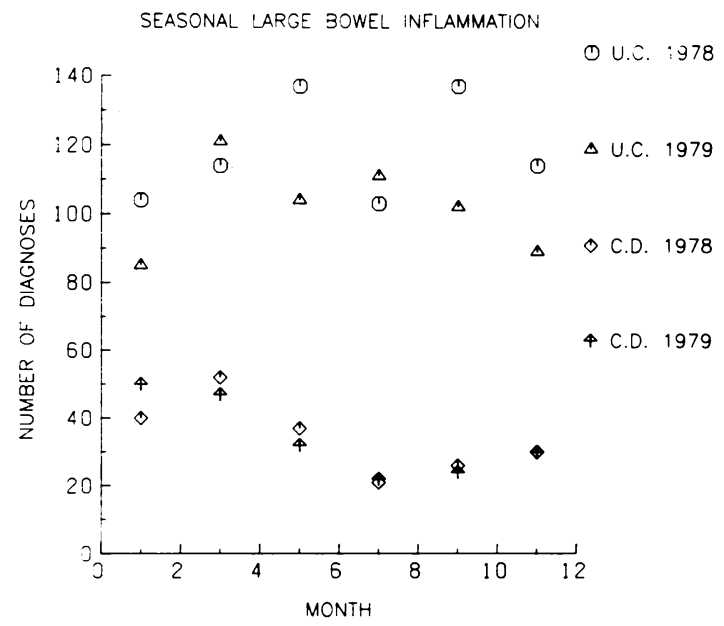

The number of diagnoses made over a period of two years of ulcerative colitis (UC) and of Crohn's disease (CD) is plotted as two-month totals. The months are given in arabic numerals and the year begins at 0 . The figure was printed by a computer.

that they provide an explanation for the nonrandom factor in the frequency of these two diagnoses.

When the average difference in the number of diagnoses made in the same two-month periods between two years, adjusted to the overall frequency of that diagnosis is compared (Table 5), the influence of seasonal variations is eliminated. The ratio of variability between the two years was found to be low $(8-19 \%)$ for the diagnosis of ulcerative and Crohn's disease as well as neoplastic disease. The ratio was $30 \%$ for the diagnosis of normal tissue and $57 \%$ for the indeterminate-non-specific colitis category. The reason for these marked variations is not obvious from this analysis. 
Table 5 Variability of the number of diagnoses between 1978 and 1979. (Ratio of the mean bimonthly difference in number of diagnoses between the two years to the overall bimonthly mean of the number of the same diagnoses, expressed as per cent)

\begin{tabular}{ll}
\hline Diagnosis & Ratio (\%) \\
\hline Ulcerative colitis & 19 \\
Crohn's disease & 11 \\
Indeterminate colitis & 57 \\
Normal & 30 \\
Adenocarcinoma & 12 \\
Adenoma & 8 \\
\hline
\end{tabular}

\section{Discussion}

The pathology records of St Mark's hospital show that the accuracy of a single biopsy diagnosis of Crohn's disease was about $40 \%$ and that of ulcerative colitis about $70 \%$. This accuracy was not different for subsequent biopsies.

A $70 \%$ accuracy rate for the biopsy diagnosis of ulcerative colitis seems reasonable considering that the pathologist is looking at such very small samples of tissue obtained from five feet of large bowel. In addition to this inherent sampling error there is also an observer error. Although ulcerative colitis is a diffuse mucosal disease in continuity, almost always involving the rectum, some patients have a first biopsy after they have received medical treatment. Treatment, such as steroid enemas alone, often leads to remission of disease in the rectum but with persistent inflammation in the colon. Furthermore, the severity of the inflammation in ulcerative colitis varies with time much more than in Crohn's disease and can go into remission spontaneously. All of these factors contribute to observer error. On the other hand, in remission the mucosa may look normal endoscopically but may be histologically abnormal, which is justification for performing a biopsy at this time in the course of the disease.

The accuracy rate for the biopsy diagnosis of Crohn's disease is also affected by sampling error but this is much increased by the discontinuous and patchy nature of the disease. Thus a high proportion of biopsies showed a normal appearance, about $30 \%$ (Tables 1 and 2) compared to about $7 \%$ for ulcerative colitis. This accounts for most of the failure rate of diagnosis. It is also true that a biopsy report of normal mucosa in the presence of radiological or endoscopic evidence of colitis favours a clinical diagnosis of Crohn's disease rather than ulcerative colitis. There is, in addition, an observer error primarily based on the fact that only about half of the cases of Crohn's disease will show characteristic granulomas. Thus a $40 \%$ accuracy rate can be regarded as reasonably good. Comparisons of accuracy rates with other laboratories would be interesting.

Crohn's disease showed a distinct seasonal variation in the frequency of diagnosis, high in the Spring and low in the Autumn, possibly corresponding to a higher rate of exacerbation in the Spring and a higher rate of remission in the Autumn. There was also a slight seasonal variation in the rate of diagnosis of ulcerative colitis with a summer maximum and a winter minimum, but this was only just perceptible. These are incidental observations which seem to account for non-random factors in the frequency of the two diagnoses at different times.

The rate of diagnosis of indeterminate colitis and of normal colon showed non-seasonal non-random variations when the same two-monthly periods between the two years concerned in the study were compared. The explanation is not obvious and not related to the rates of diagnosis of ulcerative colitis and Crohn's disease. Temporary fashions of terminology and changes of pathology trainees as they pass through the Department could contribute to this variation. The non-controversial diagnosis of adenoma and adenocarcinoma showed no nonrandom variations during the same two years.

This approach to medical audit could provide some aspects of evaluation of health care, a topic which is of increasing importance. ${ }^{4}$

\section{References}

${ }^{1}$ Morson BC, Dawson IMP. Gastrointestinal pathology. 2nd ed. Oxford: Blackwell, 1979.

${ }^{2}$ Morson BC. Pathology of inflammatory bowel disease. Gastroenterol Jpn 1980;15:184-7.

${ }^{3}$ Quenouille MH. Introductory statistics. Toronto: Pergamon Press, 1969.

4 Warner KE, Hutton RC. Cost-benefit and cost-effectiveness analysis in health care. Growth and composition of the literature. Medical Care 1980;18:1069-84.

Requests for reprints to: Dr BC Morson, Department of Pathology, St Mark's Hospital, London EC1V 2PS, England. 